\title{
Colonic Pseudo-obstruction With Transition Zone: A Peculiar Eastern Severe Dysmotility
}

\author{
Eun Mi Song, ${ }^{1}$ Jong Wook Kim, ${ }^{2}$ Sun-Ho Lee, ${ }^{1}$ Kiju Chang, ${ }^{1}$ Sung Wook Hwang, ${ }^{1}$ Sang Hyoung Park, ${ }^{1}$ Dong-Hoon Yang, ${ }^{1}$ \\ Kee Wook Jung, ${ }^{1}$ Byong Duk Ye, ${ }^{1}$ Jeong-Sik Byeon, ${ }^{1}$ Suk-Kyun Yang, ${ }^{1}$ Hyo Jeong Lee, ${ }^{3}$ Chang Sik Yu, ${ }^{4}$ Chan Wook Kim, \\ Seong Ho Park, ${ }^{5}$ Jihun Kim, ${ }^{6 *}$ and Seung-Jae Myung ${ }^{1 *}$ \\ Departments of ${ }^{1}$ Gastroenterology, ${ }^{4}$ Colon and Rectal Surgery, ${ }^{5}$ Radiology, and ${ }^{6}$ Pathology, University of Ulsan College of Medicine, Asan \\ Medical Center, Seoul, Korea; ${ }^{2}$ Department of Internal Medicine, Inje University Ilsan Paik Hospital, Goyang, Gyeonggi-do, Korea; and ${ }^{3}$ Health \\ Screening and Promotion Center, Asan Medical Center, Seoul, Korea
}

\begin{abstract}
Background/Aims
Previous studies from Korea have described chronic intestinal pseudo-obstruction (CIPO) patients with transition zone (TZ) in the colon. In this study, we evaluated the pathological characteristics and their association with long-term outcomes in Korean colonic pseudo-obstruction (CPO) patients with TZ.
\end{abstract}

\section{Methods}

We enrolled 39 CPO patients who were refractory to medical treatment and underwent colectomy between November 1989 and April 2016 (median age at symptoms onset: 45 [interquartile range, 29-57] years, males 46.2\%). The TZ was defined as a colonic segment connecting a proximally dilated and distally non-dilated segment. Detailed pathologic analysis was performed.

\section{Results}

Among the 39 patients, 37 (94.9\%) presented with TZ and 2 (5.1\%) showed no definitive TZ. Median ganglion cell density in the TZ adjusted for the colonic circumference was significantly decreased compared to that in proximal dilated and distal non-dilated segments in TZ $(+)$ patients $(9.2$ vs 254.3 and 150.5, $P<0.001)$. Among the TZ $(+)$ patients, 6 showed additional pathologic findings including eosinophilic ganglionitis $(n=2)$, ulcers with combined cytomegalovirus infection $(n=2)$, diffuse ischemic changes $(n=1)$, and heterotropic myenteric plexus $(n=1)$. During follow-up (median, 61 months), $32(82.1 \%)$ TZ $(+)$ patients recovered without symptom recurrence after surgery. The presence of pathological features other than hypoganglionosis was an independent predictor of symptom recurrence after surgery $(P=0.046)$.

\section{Conclusions}

Hypoganglionosis can be identified in the TZ of most Korean CPO patients. Detection of other pathological features in addition to TZassociated hypoganglionosis was associated with poor post-operative outcomes.

(J Neurogastroenterol Motil 2019;25:137-147)

\section{Key Words}

Colonic pseudo-obstruction; Intestinal pseudo-obstruction; Pathology; Outcomes

Received: July 10, 2018 Revised: September 19, 2018 Accepted: September 28, 2018

(a) This is an Open Access article distributed under the terms of the Creative Commons Attribution Non-Commercial License (http://creativecommons. org/licenses/by-nc/4.0) which permits unrestricted non-commercial use, distribution, and reproduction in any medium, provided the original work is properly cited.

*Correspondence: Jihun Kim and Seung-Jae Myung are equally responsible for this study. Jihun Kim, MD, PhD Department of Pathology, Asan Medical Center, University of Ulsan College of Medicine, 88 Olympic-ro 43 gil, Songpa-gu, Seoul 05505, Korea

Tel: +82-2-3010-4556, Fax: +82-2-472-7898, E-mail: Jihunkim@amc.seoul.kr

Seung-Jae Myung, MD, PhD

Department of Gastroenterology, Asan Medical Center, University of Ulsan College of Medicine, 88 Olympic-ro, 43-gil, Songpa-gu, Seoul 05505, Korea

Tel: +82-2-3010-3917, Fax: +82-2-476-0824, E-mail: sjmyung@amc.seoul.kr 


\section{Introduction}

Chronic intestinal pseudo-obstruction (CIPO) is a rare, intractable disease characterized by recurrent symptoms of bowel obstruction without demonstrable occluding lesions. Previously, studies evaluating adult CIPO patients have mainly been reported from Western countries. ${ }^{1-4}$ Most patients described were first diagnosed as having CIPO in their late teens and early 20s, requiring over 5 years from symptom onset to establish a diagnosis. The clinical course of Western CIPO patients is invariably severe ${ }^{2,3}$ with $80-90 \%$ of patients requiring surgery, one-third of patients needing long-term home total parenteral nutrition, and a significant proportion becoming opioid-dependent due to long-standing, severe abdominal pain. ${ }^{1,3,5}$ The pathology underlying CIPO involves heterogeneous changes including neuropathies, myopathies, and mesenchymopathies (interstitial cells of Cajal [ICC] abnormalities). ${ }^{6,7} \mathrm{Few}$ studies have examined the clinical and pathological characteristics of CIPO in Eastern countries. ${ }^{8}$

Studies from Korea have reported on a specific group of patients characterized by features of colonic type CIPO with a distinct transition zone (TZ) on macroscopic and microscopic evaluation. ${ }^{9-14}$ The TZ refers to a focally narrowed colonic segment connecting proximally dilated and distally non-dilated segments. Previous studies from referral centers in Korea indicated 74-79\% of patients with colonic pseudo-obstruction (CPO) showed $\mathrm{TZ}$ on radiologic studies. ${ }^{13-15}$ Clinical symptoms of Korean $\mathrm{CPO}$ patients with $\mathrm{TZ}$ were similar to those of Western CIPO patients. Recurrent sub-occlusive events with abdominal pain, distension, nausea, and vomiting were present and marked dilations of the bowel visualized by computed tomography (CT) scan or radiography were also observed. ${ }^{13,14}$ However, Korean CPO patients with TZ showed less small bowel involvement ${ }^{14}$ and favorable clinical course, unlike Western CIPO patients. $^{13-15}$

Few studies have reported pathological analysis of $\mathrm{TZ},{ }^{9,11,13}$ in which a significant reduction of ganglion cells defined as segmental hypoganglionosis was found. The number of ICC also decreased in 32.2-60.0\% of patients. ${ }^{11,13}$ Moreover, functional and molecular analysis showed a reduced response to depolarization and a decreased number of neural nitric oxide synthase (nNOS)-positive cells in the TZ. ${ }^{10}$ However, even in these studies, evaluation was limited to only focal colonic segments, and not to the whole resected colon including the proximally dilated and distally non-dilated segments. ${ }^{11,13}$

Therefore, our objective was to evaluate Korean $\mathrm{CPO}$ patients with radiologically confirmed TZ by detailed pathologic analysis of the resected colon specimen. Next, we assessed the long-term outcomes of TZ-associated CPO patients according to the underlying pathologic characteristics.

\section{Materials and Methods}

\section{Study Population}

This was a retrospective study performed in a tertiary referral center in Seoul, South Korea. Overall, 129 patients were referred with a suspicion of CPO to our center between November 1989 and April 2016. CPO diagnosis was made when patients fulfilled the following criteria: (1) recurrent episodes with symptoms mimicking mechanical obstruction including abdominal pain and abdominal bloating; (2) bowel dilatation and/or intestinal air-fluid levels on abdomen X-ray and/or CT scan; and (3) no evidence of structural disease causing obstruction on upper and lower endoscopy, CT scan, small bowel series, and barium enema. ${ }^{8}$ Among the 84 CPO-confirmed patients, 38 were managed conservatively, while the remaining 46 underwent colectomy, and of these, 7 patients were excluded because the pathologic specimen was insufficient. Thirty-nine patients were finally enrolled in this study (Supplementary Fig. 1). The Institutional Review Board of Asan Medical Center approved the protocol of this study (No. 2016-1145).

\section{Pathological Examination}

All resected specimens were opened, photographed, and fixed with $10 \%$ neutral buffered formalin on corkboard. Dilated and apparently normal segments were identified, and maximum and minimum internal circumferences were measured. Segments, which connected dilated and non-dilated areas, were considered TZ. Longitudinal sections for microscopic examination were taken every 10 $\mathrm{cm}$ from the proximal to the distal part of the resected specimen. For the $\mathrm{TZ}$, sections were taken contiguously along the long axis of the pathological segment.

Myenteric cell bodies, identified by their characteristic microscopic morphology, such as Nissl substance, large vesicular nuclei, and single prominent nucleoli, were counted per ganglion (Supplementary Fig. 2A). Calretinin immunostaining was used only when no unequivocal ganglion cells were identifiable with hematoxylin and eosin (H\&E) staining (Supplementary Fig. 2B). The number of ganglion cells in the myenteric plexus was counted per centimeter. ${ }^{16}$ Since luminal dilatation might decrease ganglion cell number in proportion to the luminal circumference, we multiplied the gan- 
glion cell number per centimeter by the mean internal circumference in a given intestinal segment and chose the product as a ganglion cell density. To evaluate the potential contribution of ICCs to intestinal motility disturbances, we counted the number of CD117positive ICC in 10 high magnification fields ( $\times 40$ objective lens) (Supplementary Fig. 2C). Since mast cells also express CD117 (Supplementary Fig. 2D), we only counted CD117-positive cells that showed unequivocal dendritic cell processes.

In addition, we counted the number of eosinophils per high power field. Eosinophilic ganglionitis was defined as prominent eosinophilic infiltration in and around the myenteric plexus, the number of which is no less than 10/high power field based on previous case reports. ${ }^{17,18}$

\section{Immunohistochemistry}

To identify ganglion cells and ICC, formalin-fixed paraffinembedded tissue sections were stained with anti-Calretinin antibodies (rabbit monoclonal, clone DC8, Catalog No. 18-0211; dilution 1:400; Zymed, Camarillo; CA, USA,) and anti-CD117 antibodies (rabbit polyclonal, Catalog No. A4502; dilution 1:400; DAKO, Glostrup, Denmark,), respectively. All immunostaining studies were performed using a BenchMark XT automatic immunostaining device with OptiView 3,3'-Diaminobenzidine Immunohistochemistry Detection Kit (Ventana Medical Systems, Tuscon, AZ, USA) according to the manufacturer's instructions.

\section{Data Collection and Disease Outcome Measurement}

We compared the baseline characteristics of $\mathrm{CPO}$ patients according to pathological characteristics including the presence of $\mathrm{TZ}$ and additional pathologic features. Data including patient demographics, symptoms, results of radiologic studies (abdomen simple X-ray and CT scan), results of endoscopy (upper and lower endoscopy), and laboratory findings were collected by reviewing the medical records. Symptom patterns of patients were classified as follows: (1) acute onset (patients who had symptoms that started within 6 months from CPO diagnosis), (2) acute exacerbation of chronic symptoms (patients whose symptoms were suddenly aggravated and long-standing), and (3) chronic intractable symptoms (patients who had progressive and uncontrolled symptoms lasting more than 6 months). ${ }^{9}$

The clinical outcomes including disease recurrence, which was defined as re-hospitalization and/or re-operation for treating symptoms and complications of $\mathrm{CPO}$ were compared according to the pathologic characteristics. In addition, we evaluated the factors associated with disease recurrence. For patients who had not visited the outpatient department for an extended period, we collected data by telephone interview.

\section{Statistical Methods}

Continuous variables are expressed as medians with interquartile ranges (IQRs) and categorical variables as numbers with percentages (\%). The chi-squared or Fisher's exact test was used to compare categorical variables, and the Mann-Whitney $U$ test for continuous variables between groups. The cumulative probability of disease recurrence after surgery was calculated using the KaplanMeier method and comparisons between the groups was performed using the log-rank test. To evaluate factors associated with disease recurrence, a logistic regression model was used. All variables with $P$-values $<0.1$ in univariate analysis were included in the multivariate model. $P$-value of $<0.05$ was considered statistically significant. All statistical analyses were performed with the aid of SPSS version 21.0 software for Windows (IBM SPSS; IBM Co, Armonk, NY, USA).

\section{Results}

\section{Clinical Characteristics}

Table 1 shows the clinical characteristics of patients. The median age of symptom onset of the 39 patients enrolled in this study was 45 years (IQR, 29-57 years). The median duration from the symptom onset to CPO diagnosis was 2.0 years (IQR, 1.0-5.3 years). The most common presenting symptom was abdominal distension (92.3\%), followed by abdominal pain (79.5\%), constipation (76.9\%), and nausea/vomiting (35.9\%). Among 39 patients, 10 patients (25.6\%) had diabetes mellitus and 2 patients $(5.1 \%)$ had thyroid disease. Sixteen patients $(41.0 \%)$ had previous history of abdominal surgery. In the abdomen CT scan, small bowel dilation was demonstrated in 23 (59.0\%) patients. Among 39 patients, 13 (33.3\%) underwent emergency surgery due to intractable gastrointestinal symptoms, particularly when accompanied by signs suggesting septic conditions. Twenty-six patients (66.7\%) underwent elective surgery due to symptoms refractory to medical treatment.

\section{Pathologic Analyses}

The pathologic characteristics of each patient are summarized in Table 2. Overall, 37/39 (94.9\%) patients showed pathologically detectable TZ. Median ganglion cell density in the TZ adjusted for the colonic circumference was significantly decreased compared to that in proximal dilated and distal non-dilated segments $(9.2$ 
Table 1. Baseline Characteristics

\begin{tabular}{|c|c|c|c|c|c|}
\hline \multirow[b]{2}{*}{ Variables } & \multirow{2}{*}{$\begin{array}{l}\text { All patients } \\
(\mathrm{n}=39)\end{array}$} & \multicolumn{2}{|c|}{$\mathrm{TZ}(+)$ group } & \multirow{2}{*}{$\begin{array}{l}\mathrm{TZ}(-) \text { group } \\
\quad(\mathrm{n}=2)\end{array}$} & \multirow[b]{2}{*}{$P$-value } \\
\hline & & $\begin{array}{l}\text { Classic TZ group } \\
\quad(\mathrm{n}=31)\end{array}$ & $\begin{array}{l}\text { Atypical TZ group } \\
\qquad(\mathrm{n}=6)\end{array}$ & & \\
\hline Age at symptom onset (yr) & $45(29-57)$ & $41(29-62)$ & $50(15.3-57.8)$ & $31.5(13.0-31.5)$ & 0.843 \\
\hline Age at surgery (yr) & $49(34-65)$ & $45(34-65)$ & $57(47.8-66.0)$ & $36.0(20.0-36.0)$ & 0.435 \\
\hline Male sex & $18(46.2)$ & $13(41.9)$ & $4(66.7)$ & $1(50.0)$ & 0.383 \\
\hline Duration from onset to diagnosis (yr) & $2.0(1.0-5.25)$ & $2.0(1.0-4.5)$ & $1.5(1.0-16.3)$ & $3.5(1.0-3.5)$ & 0.141 \\
\hline Symptom pattern & & & & & 0.140 \\
\hline Acute onset & $9(23.1)$ & $8(35.8)$ & $1(16.7)$ & $0(0.0)$ & \\
\hline Acute exacerbation of chronic symptoms & $16(41.0)$ & $15(48.4)$ & $1(16.7)$ & $0(0.0)$ & \\
\hline Chronic intractable symptoms & $14(35.9)$ & $8(25.8)$ & $4(66.7)$ & $2(100.0)$ & \\
\hline BMI & $20.3(17.9-22.6)$ & $20.3(17.6-22.3)$ & $21.4(19.5-24.2)$ & $20.7(17.9-20.7)$ & 0.248 \\
\hline Dilatation of small bowel & $23(59.0)$ & $12(61.3)$ & $2(33.3)$ & $2(100.0)$ & 0.213 \\
\hline $\mathrm{TZ}$ on abdominal CT & $36(92.3)$ & $30(96.8)$ & $6(100)$ & $0(0.0)$ & $>0.999$ \\
\hline Location of $\mathrm{TZ}$ & & & & & 0.068 \\
\hline Transverse-descending colon & $30(76.9)$ & $27(87.1)$ & $3(50.0)$ & - & \\
\hline Sigmoid colon-rectum & $7(17.9)$ & $4(12.9)$ & $3(50.0)$ & - & \\
\hline
\end{tabular}

${ }^{\mathrm{a}} P$-value: classic transition zone (TZ) group vs atypical TZ group.

BMI, body mass index; DM, diabetes mellitus; CT, computed tomography.

Values are expressed as n (\%) or median (interquartile range).

vs 254.3 and 150.5, $P<0.001$ ) (Fig. 1). Generally, ganglion cell densities in colonic segments just distal to $\mathrm{TZ}$ were lower by more than $50 \%$ of those in adjacent normal ganglionated segments. In 3 patients (patients No. 29, 30, and 31), however, only mild decrease of ganglion cell density (decrease between $15 \%$ and $50 \%$ of the ganglion cell density in adjacent normal ganglionated segments) was observed. Locations of the TZs were the descending colon $(\mathrm{n}=$ $16[41.0 \%])$, transverse colon $(n=14[35.9 \%])$, rectum $(n=4$ $[10.3 \%])$, and sigmoid colon $(n=3[7.7 \%])$. Based on pathological analysis, patients were classified as those (1) with pathologically identified TZ (TZ [+] group, $\mathrm{n}=37$ [94.9\%]) and (2) without definable TZ (TZ $[-]$ group, $\mathrm{n}=2[5.1 \%])$. The TZ $(+)$ group was subdivided into subsets (i) cases with typical hypoganglionosis (classic TZ group, $\mathrm{n}=31$ [79.5\%]); and (ii) cases with hypoganglionic $\mathrm{TZ}$ and additional pathologic features (atypical $\mathrm{TZ}$ group, $\mathrm{n}=$ $6[15.4 \%])$.

\section{Typical hypoganglionosis with transition zone (classic transition zone group)}

Most resected specimens showed marked luminal dilatation in proximal segments and distinctive $\mathrm{TZ}$ and non-dilated distal segments. An example (patient No. 13) is shown in Figure 2A. In this specimen, while dilated proximal segments and non-dilated distal segments were present in the myenteric plexus with abundant ganglion cells (Fig. 2B), the TZ and approximately $10 \mathrm{~cm}$ of non- dilated segment distal to TZ showed atrophic Schwann cells with markedly decreased ganglion cells (Fig. 2C). The ganglion cell density, calculated by multiplication of the ganglion cell count per centimeter by the mean internal circumference, gradually decreased from the distal part of the $\mathrm{TZ}$, reaching the nadir at the beginning of the distal non-dilated segment (Fig. 2D). The decrease continued along the 10-cm length (the hypoganglionic segment), and the ganglion cell density gradually recovered to its normal level (Fig. 2D). The degree of decrease in ganglion cell density varied from a ratio of 0.5 (hypoganglionic segment [TZ]/normal segment, patient No. 31) to total aganglionosis in affected segments (patient No. 22) (median $=0.10 ;$ IQR, 0.06-0.20) and the length of hypoganglionic segments ranged from $5 \mathrm{~cm}$ to $120 \mathrm{~cm}$ (median $=30$ $\mathrm{cm}$; IQR, 20-50 cm) (Table 2). Interestingly, in patient No. 36, two hypoganglionic segments were found separated by an intervening segment with normal ganglion cell density; thus, the gross $\mathrm{TZ}$ was located just proximal to the first hypoganglionic segment.

\section{Hypoganglionosis with transition zone and other additional pathologic features (atypical transition zone group)}

In 6 patients, pathological features other than typical hypoganglionosis included eosinophilic ganglionitis $(\mathrm{n}=2)$, ulcers with/ without combined cytomegalovirus (CMV) infection $(n=2)$, ischemic changes $(n=1)$, and evidence of heterotopic myenteric 
Table 2. Pathological Characteristics of Colonic Pseudo-obstruction Patients

\begin{tabular}{|c|c|c|c|c|c|c|}
\hline \multirow[b]{2}{*}{ No. } & \multicolumn{3}{|c|}{ Ganglion cell count $\times$ mIC } & \multirow{2}{*}{$\begin{array}{l}\mathrm{TZ}^{\mathrm{b}} \text { length } \\
\quad(\mathrm{cm})\end{array}$} & \multirow[b]{2}{*}{ Distal RM } & \multirow[b]{2}{*}{ Comments } \\
\hline & $\begin{array}{l}\text { Proximal } \\
\text { dilated }\end{array}$ & $\mathrm{TZ}$ & $\begin{array}{l}\text { Distal non- } \\
\text { dilated }^{\mathrm{a}}\end{array}$ & & & \\
\hline 1 & 122.9 & 3.2 & 79.4 & 50 & Normal & \\
\hline 2 & 251.5 & 18.0 & 252.9 & 30 & Normal & \\
\hline 3 & 236.0 & 8.8 & 150.5 & 50 & Normal & \\
\hline 4 & 182.5 & 14.2 & 201.6 & 20 & Normal & \\
\hline 5 & 402.8 & 37.7 & 327.6 & 30 & Normal & \\
\hline 6 & 320.0 & 23.9 & 278.5 & 30 & Normal & \\
\hline 7 & 237 & 20.3 & 167.9 & 45 & Normal & \\
\hline 8 & 287.5 & 5.4 & 85.9 & 10 & Normal & \\
\hline 9 & 418.2 & 2.2 & 138.7 & 20 & Normal & \\
\hline 10 & 253.1 & 8.3 & 131.8 & 20 & Normal & Ulcers \\
\hline 11 & 281.3 & 8.4 & 163.2 & 22 & Normal & \\
\hline 12 & 199.1 & 22.9 & 112.9 & 6 & Normal & Ischemic colitis in proximal segment \\
\hline 13 & 312.6 & 4.5 & 237.4 & 25 & Normal & \\
\hline 14 & 188.2 & 0.6 & 56.0 & 50 & Normal & \\
\hline 15 & 190.0 & 25.4 & 203.1 & 40 & Normal & \\
\hline 16 & 281.2 & 2.4 & 174.9 & 45 & Normal & Ulcer with CMV \\
\hline 17 & 382.3 & 30.5 & NA & $120^{\mathrm{b}}$ & Hypoganglionic & \\
\hline 18 & 266.1 & 25.7 & NA & $25^{\mathrm{b}}$ & Hypoganglionic & \\
\hline 19 & 435.0 & 12.5 & NA & $5^{\mathrm{b}}$ & Hypoganglionic & \\
\hline 20 & 200.0 & 0.2 & NA & $80^{\mathrm{b}}$ & Hypoganglionic & \\
\hline 21 & 53.5 & 14.7 & NA & $5^{\mathrm{b}}$ & Hypoganglionic & \\
\hline 22 & 280.6 & 0.0 & NA & 28 & Hypoganglionic & Aganglionosis from the ileocecal valve \\
\hline 23 & 112.4 & 0.8 & NA & 15 & Hypoganglionic & Aganglionosis in distal $12 \mathrm{~cm}$ \\
\hline 24 & 286.4 & 9.2 & NA & 70 & Hypoganglionic & Eosinophilic ganglionitis \\
\hline 25 & 190.5 & 2.8 & 24.0 & 50 & Slightly hypoganglionic & \\
\hline 26 & 349.0 & 41.5 & 95.4 & 30 & Slightly hypoganglionic & \\
\hline 27 & 217.0 & 13.3 & 71.4 & 30 & Slightly hypoganglionic & \\
\hline 28 & 587.3 & 5.2 & 105.8 & 30 & Slightly hypoganglionic & \\
\hline 29 & 215.2 & 85.7 & 242.2 & 10 & Normal & Mild form \\
\hline 30 & 396.7 & 126.2 & 238.0 & 30 & Normal & Mild form \\
\hline 31 & 255.4 & 121.5 & $\mathrm{NA}$ & $30^{\mathrm{b}}$ & Hypoganglionic & Mild form, diverticulitis, eosinophilic ganglionitis \\
\hline 32 & 108.6 & 13.0 & 84.5 & 15 & Normal & \\
\hline 33 & 148.0 & 2.5 & NA & 2 & Hypoganglionic & \\
\hline 34 & 192 & $\mathrm{NA}$ & NA & NA & Proximal to $\mathrm{TZ}$ & \\
\hline 35 & 333 & NA & NA & NA & Proximal to $\mathrm{TZ}$ & Ulcer with CMV \\
\hline 36 & 152 & 2.8 & 40.0 & $5 / 10$ & Slightly hypoganglionic & Two hypoganglionic segments \\
\hline 37 & NA & 0.7 & NA & Entire & Hypoganglionic & Ischemic colitis \\
\hline 38 & 330.0 & NA & 286.7 & NA & Normal & $\begin{array}{l}\text { Heterotopic myenteric plexus in outer longitudinal } \\
\text { muscle in } \mathrm{TZ}\end{array}$ \\
\hline 39 & 123.8 & $\mathrm{NA}$ & NA & NA & Myopathic changes & Loss of smooth muscle fibers with interstitial fibrosis \\
\hline
\end{tabular}

${ }^{a}$ Segments that had apparently normal ganglion cell number, but were distal to those with decreased ganglion cells.

${ }^{b}$ Length may be incorrect because hypoganglionic segment had not been completely resected.

$\mathrm{mIC}$, mean internal circumference $(\mathrm{cm})$; TZ, transition zone; RM, resection margin; CMV, cytomegalovirus; NA, not assessed.

plexus ( $\mathrm{n}=1$ ) (Fig. 3). Eosinophilic ganglionitis (cases No. 24 and 31) was characterized by the infiltration of eosinophils specifically in the myenteric plexus of the distal non-dilated segment (Fig. 3A and 3B). In CMV-infected cases (cases No. 16 and 35), geographic ulcers were observed where several CMV inclusions were identified through immunohistochemistry analysis (Fig. 3C and 3D). CMV 

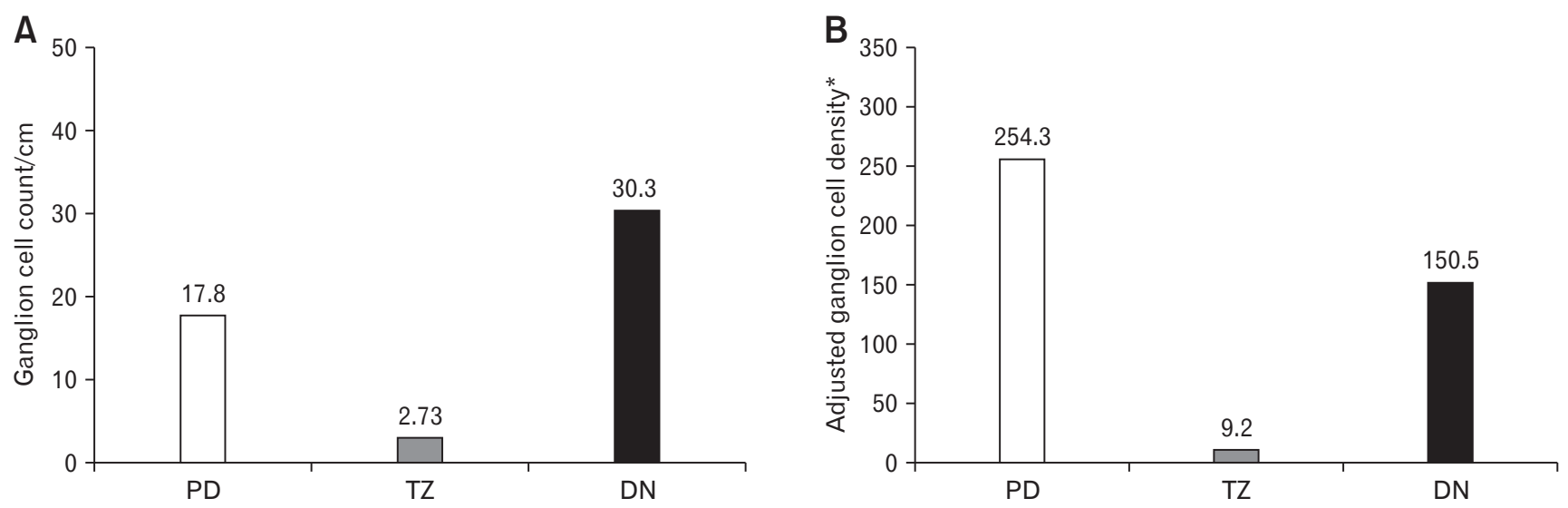

Figure 1. Ganglion cell count (A) and ganglion cell density (B) differences between the transition zone (TZ) and other colonic segment. The median value of each groups are presented. ${ }^{*}$ Ganglion cell count $/ \mathrm{cm} \times$ internal circumference $(\mathrm{cm})$. PD, proximal dilated; DN, distal non-dilated.
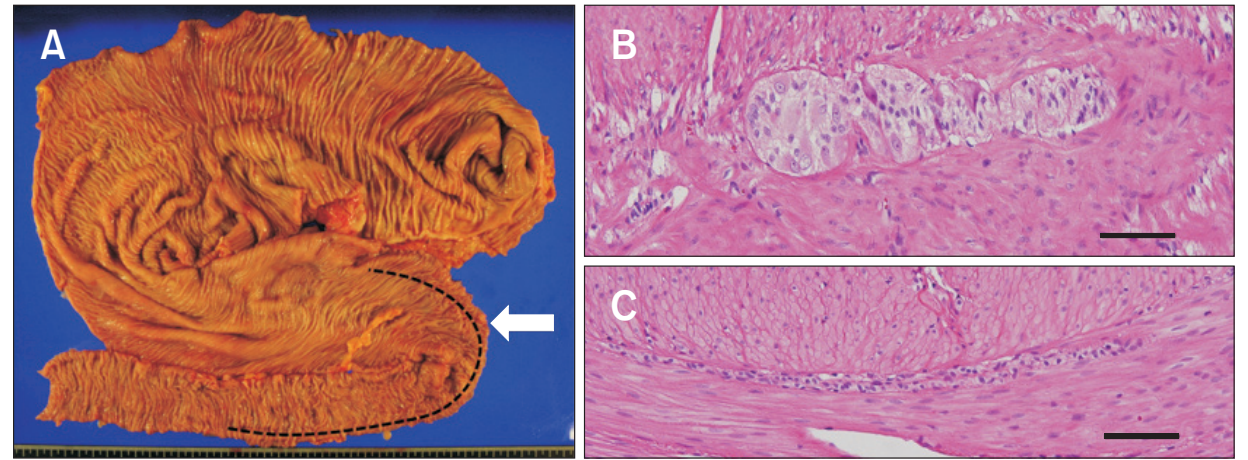

D

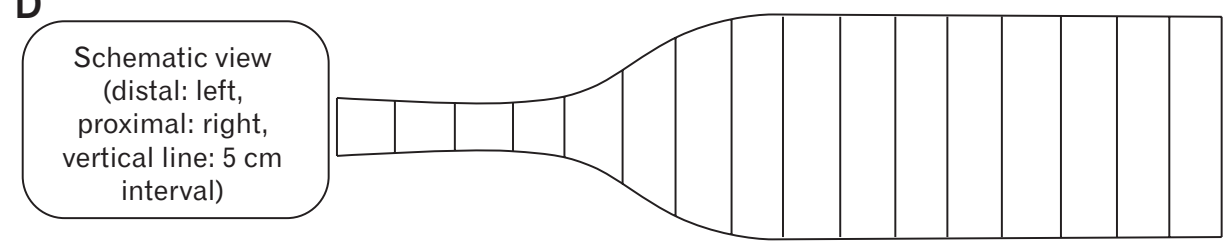

\begin{tabular}{|c||c|c|c|c|c|c|c|c|c|c|c|c|c|c|c|c|c|}
\hline Number of ganglion cells/cm [A] & 65.0 & 37.8 & 0.4 & 0.0 & 0.4 & 2.5 & 8.8 & 21.0 & 25.0 & 15.0 & 23.2 & 19.1 & 21.8 & 22.9 & 17.6 & 15.5 \\
\hline Mean IC per interval $(\mathrm{cm})[\mathrm{B}]$ & 4.5 & 4.5 & 4.5 & 4.5 & 4.5 & 7.4 & 10.3 & 13.2 & 15.5 & 15.5 & 15.5 & 15.5 & 15.5 & 14.5 & 13.0 & 12.0 \\
\hline$[\mathrm{A}] \times[\mathrm{B}]$ & 292 & 170 & 1.8 & 0.0 & 1.8 & 19 & 91 & 277 & 388 & 233 & 360 & 296 & 338 & 332 & 229 & 186 \\
\hline
\end{tabular}

Figure 2. Pathologic characteristics of typical hypoganglionosis with transition zone (TZ) (patient No. 13). (A) Gross photograph shows markedly dilated proximal colonic segments, non-dilated distal segments, and TZ connecting them (arrow). Dashed line indicates hypoganglionic segment. (B) Myenteric plexus of the proximal dilated segment shows abundant ganglion cells and Schwann cells $(\times 40$ objective lens, scale bar $=50 \mu \mathrm{m})$. $(\mathrm{C})$ Myenteric plexus in TZ shows atrophic Schwann cells without ganglion cells or inflammation $(\times 40$ objective lens, scale $=50 \mu \mathrm{m})$. (D) Schematic view of a novel pathologic analysis. In this particular case, sections were taken every 5 -cm (intervals of vertical lines of upper panel). Numbers of ganglion cells are markedly decreased especially in the distal $\mathrm{TZ}$ and the decrease in ganglion cells is observed for a certain length (approximately $10 \mathrm{~cm}$ in this case) after TZ. Then, the number of ganglion cells recovers thereafter. The recovered ganglion cell numbers are seemingly larger than those of proximal dilated segment, but both become similar when the internal circumference (IC) is taken into account (lower panel).

ulcers were observed in the proximal dilated segment (patients No. 16 and 35) and distal non-dilated segment (patient No. 16). Patient No. 12 showed a proximal dilated segment with reddish mucosal changes and mucosal necrosis and transmural ischemic changes were observed microscopically (Fig. 3E and 3F). In patient No. 38, the $\mathrm{TZ}$ was prominent, but without visible decrease in ganglion cell density (Table 2). Instead, there were several heterotopic myenteric plexuses within the outer longitudinal muscle layer (Fig. 3G and 
$3 \mathrm{H})$.

\section{Colonic pseudo-obstruction without definable transition zone (transition zone [-] group)}

Of 39 patients, 2 (5.4\%) showed no identifiable TZ (Table 3). In patient No. 37, diffuse hypoganglionosis with ischemic changes was observed (Fig. 4A and 4B). In patient No. 39, there was a severe loss of smooth muscle fibers and interstitial fibrosis, suggesting degenerative myopathy (Fig. 4C and 4D). In cases of the TZ (-) group and atypical TZ without hypoganglionosis (patient No. 38 with heterotopic myenteric plexus), we hypothesized that the differences in ICC number might explain the CPO symptoms. However, the ICC number was not decreased in the TZ of the resected specimen of patient No. 38 and was not significantly decreased in a patient in the TZ (-) group (patient No. 40) compared to normal segments present in the typical TZ group (Supplementary Table 1).
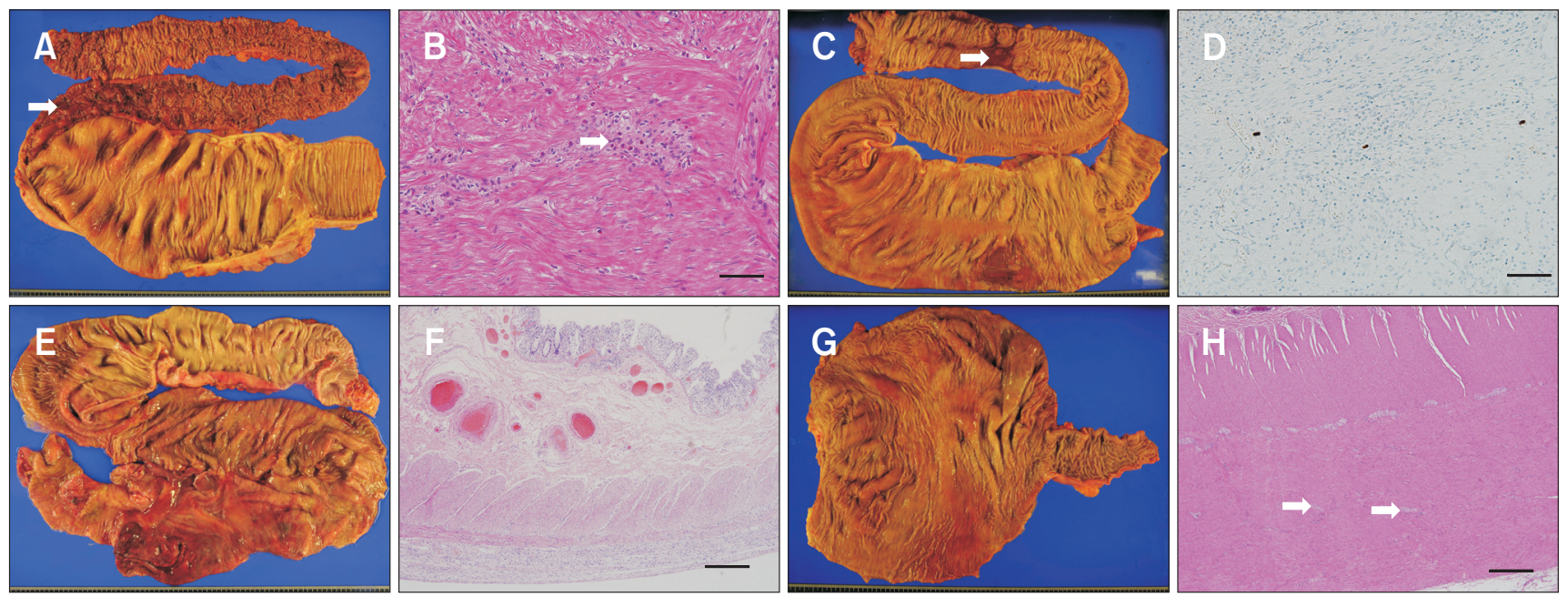

Figure 3. Representative photomicrographs for segmental hypoganglionosis cases with other specific features. (A, B) A segmental hypoganglionosis case with eosinophilic ganglionitis (patient No. 24). Colonic segment distal to the transition zone shows reddish discoloration (arrow) (A). Several eosinophils are observed along the hypoganglionic myenteric plexus (arrow) (B) $(\mathrm{H} \& \mathrm{E}, \times 20$ objective lens, scale bar $=100 \mu \mathrm{m}) .(\mathrm{C}, \mathrm{D})$ A segmental hypoganglionosis case with cytomegalovirus (CMV) infection (patient No. 16). Several geographic ulcers (arrow) are observed in distal ganglionated segment (arrow) (C). CMV immunostaining reveals several CMV inclusions (brown dots) (D) (CMV immunohistochemistry, $\times 20$ objective lens, scale bar $=100 \mu \mathrm{m}$ ). (E, F) A segmental hypoganglionosis case with ischemia (patient No. 12). Proximal dilated segment shows reddish mucosal discoloration and loss of semilunar folds (E). Transmural ischemic changes are seen $(\mathrm{F})(\mathrm{H} \& \mathrm{E}, \times 4$ objective lens, scale bar $=500 \mu \mathrm{m}) .(\mathrm{G}, \mathrm{H})$ An intestinal pseudo-obstruction case with transition zone without hypoganglionosis (patient No. 38). Marked dilatation of proximal colon with prominent transition zone $(G)$. Heterotopic ganglions are observed in outer longitudinal muscle layer (arrows) (H) (H\&E, $\times 4$ objective lens, scale bar $=500 \mu \mathrm{m})$.

Table 3. Pathologic Classification of Colonic Pseudo-obstruction Patients With and Without Transition Zone

\begin{tabular}{ccccc} 
Classification & TZ & $\begin{array}{c}\text { Hypogan- } \\
\text { glionosis }\end{array}$ & $\begin{array}{c}\text { Disease recurrence } \\
\text { after surgery }(\mathrm{n}[\%])\end{array}$ & Comment \\
\hline $\mathrm{TZ}(+)$ group $(\mathrm{n}=37)$ & & & $5(15.6)$ & $2(6.5)$ \\
Classic TZ group $(\mathrm{n}=31)$ & + & + & $3(50.0)$ & Eosinophilic ganglionitis $(\mathrm{n}=2)$ \\
Atypical TZ group $(\mathrm{n}=6)$ & + & + & & Ulcers with combined CMV infection $(\mathrm{n}=2)$ \\
& & & & Heterotopic myenteric plexus $(\mathrm{n}=1)$ \\
$\mathrm{TZ}(-)$ group $(\mathrm{n}=2)$ & & & $2(100.0)$ & \\
Diffuse hypoganglionosis $(\mathrm{n}=1)$ & - & + & $1(100.0)$ & \\
Degenerative myopathy $(\mathrm{n}=1)$ & - & - & $1(100.0)$ &
\end{tabular}

$\mathrm{TZ}$, transition zone; CMV, cytomegalovirus. 

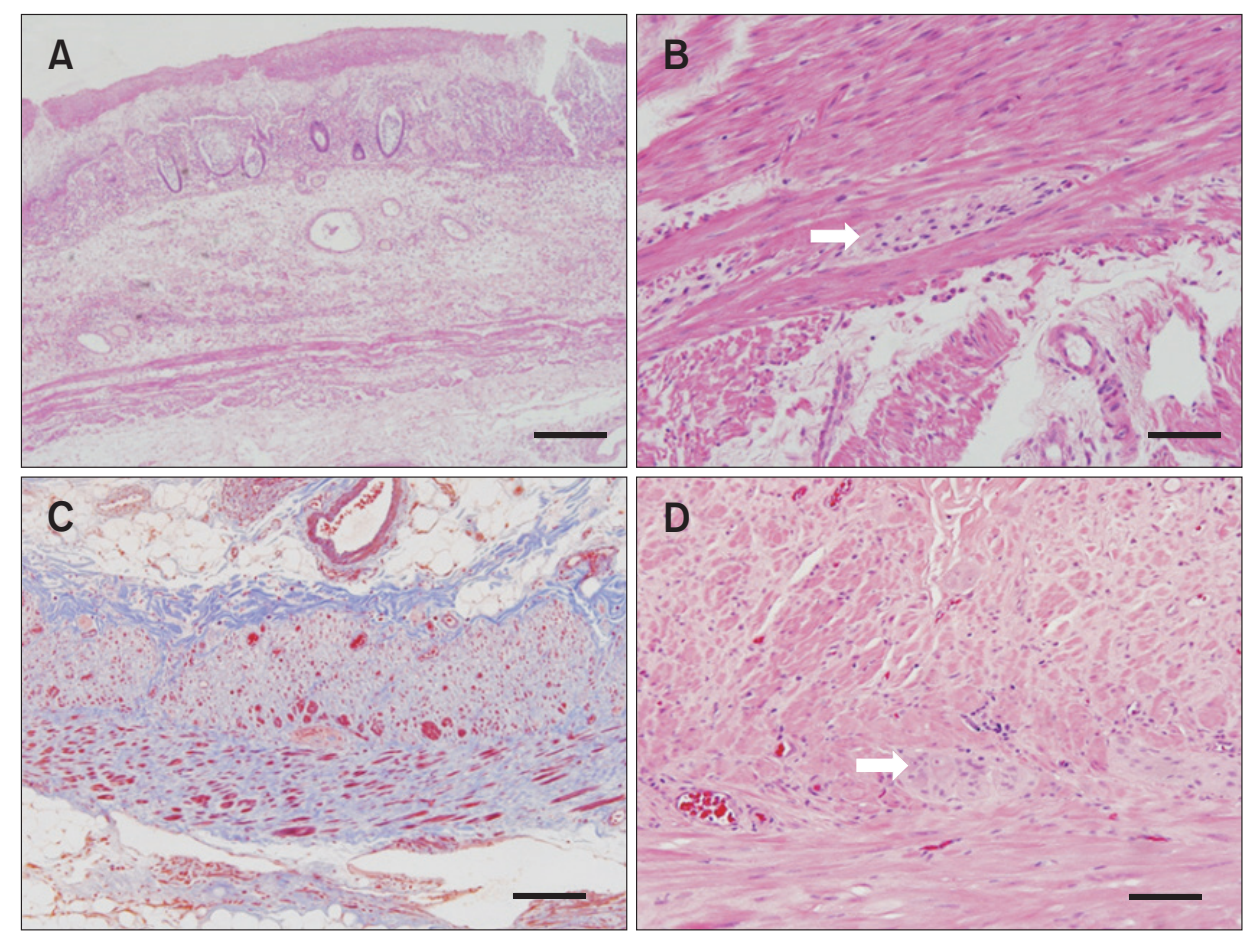

Figure 4. Microscopic appearance of colonic pseudo-obstruction without transition zone. (A, B) Diffuse hypoganglionosis with ischemia (patient No. 37). Transmural ischemic necrosis is seen (A) $(\mathrm{H} \& \mathrm{E}, \times 4$ objective lens, scale bar $=$ $500 \mu \mathrm{m})$. Note that ganglion cell is absent in the myenteric plexus (arrow) (B) (hematoxylin and eosin $[\mathrm{H} \& \mathrm{E}], \times 400$ objective lens, scale bar $=50 \mu \mathrm{m}),(\mathrm{C}$, D) Myopathic changes without hypoganglionosis (patient No. 39). Proper muscle layer shows severe loss of smooth muscle fibers and marked interstitial fibrosis (C) (Masson's Trichrome, $\times 10$ objective lens, scale bar $=200 \mu \mathrm{m}$ ). Ganglion cells are present in the myenteric plexus (arrow) (D) (H\&E, $\times 20$ objective lens, scale bar $=100 \mu \mathrm{m})$.

Table 4. Clinical Course of Colonic Pseudo-obstruction Patients

\begin{tabular}{|c|c|c|c|c|c|}
\hline \multirow[b]{2}{*}{ Variables } & \multirow[b]{2}{*}{ Overall } & \multicolumn{2}{|c|}{$\mathrm{TZ}(+)$ group } & \multirow{2}{*}{$\begin{array}{l}\mathrm{TZ}(-) \text { group } \\
(\mathrm{n}=2)\end{array}$} & \multirow[b]{2}{*}{$P$-value } \\
\hline & & $\begin{array}{c}\text { Classic TZ group } \\
(\mathrm{n}=31)\end{array}$ & $\begin{array}{l}\text { Atypical TZ group } \\
(\mathrm{n}=6)\end{array}$ & & \\
\hline Duration of follow up (yr) & $5.1(1.8-8.0)$ & $5.0(1.5-8.8)$ & $6.0(3.3-7.0)$ & $4.8(1.1-4.8)$ & 0.825 \\
\hline Number of sub-occlusive episodes before surgery & $3.0(3.0-4.0)$ & $3.0(3.0-4.0)$ & $2.5(2.0-3.3)$ & 5.0 & 0.282 \\
\hline Post-surgical outcomes & & & & & 0.022 \\
\hline Without disease recurrence & $32(82.1)$ & $29(93.5)$ & $3(50.0)$ & $0(0.0)$ & \\
\hline With disease recurrence & $7(17.9)$ & $2(6.5)$ & $3(50.0)$ & $2(100.0)$ & \\
\hline Re-hospitalization & $7(17.9)$ & $2(6.5)$ & $3(50.0)$ & $2(100.0)$ & \\
\hline Re-operation & $2(5.1)$ & $0(0.0)$ & $0(0.0)$ & $2(100.0)$ & \\
\hline
\end{tabular}

${ }^{a} P$-value: classic transition zone (TZ) group vs atypical TZ group.

Values are expressed as median (interquartile range) or $\mathrm{n}(\%)$.

\section{Differences in Clinical Characteristics and Outcomes According to Pathology}

We compared clinical characteristics according to pathologic groups. In classic TZ group, 35.8\% of patients presented with acute-onset obstructive symptoms. Whereas, only one patient of atypical TZ group had acute-onset symptoms and $66.7 \%$ of atypical TZ group complained progressive medically-refractory chronic constipation, although the difference did not reach statistical significance $(P=0.140)$. The specific types of presenting symptoms including abdominal distension and abdominal pain was not significantly different between the 2 groups. In addition, underlying comorbidities were not significantly different between the 2 groups as well. In the classic $\mathrm{TZ}$ group, the $\mathrm{TZ}$ was observed most frequently in the descending colon (48.4\%). However, the TZ was often located in the rectosigmoid area in patients with atypical $\mathrm{TZ}$ compared to the classic $\mathrm{TZ}$ group (50.0\% vs $13.0 \%, P=0.065)$.

We evaluated clinical outcomes according to pathologic groups during the follow-up period (median 5.1 years; IQR, 1.8-8.0 years). In the classic TZ group, 29 patients (93.5\%) completely recovered without any residual symptoms after colectomy. However, 3 patients 
$(50.0 \%)$ of the atypical TZ group were treated for recurrent subocclusive episodes after colectomy $(P<0.001$; Table 4 and Supplementary Fig. 3). Only 2 patients were in the TZ (-) group and both complained of chronic intractable constipation at diagnosis. After colectomy, recurrent obstructive symptoms occurred in these patients and both underwent additional abdominal surgery during follow-up (Table 4). One patient died from severe electrolyte imbalance despite prolonged total parenteral nutrition.

\section{Clinical Factors Associated With Symptom Recurrence After Surgery in the Transition Zone (+) Group}

We evaluated factors associated with symptom recurrence after colectomy in the TZ $(+)$ group (Supplementary Table 2). The presence of combined additional pathologic features other than typical hypoganglionosis was the only statistically significant associating factor of disease recurrence $(\mathrm{OR}, 14.5 ; 95 \% \mathrm{CI}, 1.692-124.239 ; P=$ $0.015)$.

\section{Discussion}

In this retrospective study including 39 Korean CPO patients, we evaluated the pathologic characteristics of $\mathrm{TZ}$ and its relationship with patient outcomes. Overall, 37/39 (94.9\%) patients showed evidence of TZ on pathological analysis and segmental hypoganglionosis was demonstrated in the $\mathrm{TZ}$ of these Korean $\mathrm{CPO}$ patients. Moreover, detection of additional specific pathologic features in association with $\mathrm{TZ}$-associated hypoganglionosis was associated with poor post-surgical outcomes.

Previous reports have described differences in disease characteristics between Korean and Western CIPO patients. The age at diagnosis of Western patients was between the ages of 15 and 30, whereas in Korean CPO patients' age ranged between 40 to 50 years. ${ }^{1,2}$ Small bowel abnormalities identified by the dilatation observed in radiologic studies was rare in Korean CPO patients. In Western patients, 36.4-100\% showed abnormal findings on small bowel manometry. However, in Korean CPO patients, only 20$60 \%$ of patients showed small bowel abnormalities. ${ }^{14,15}$ The most notable difference regarded disease outcomes. In Western studies, the course of disease has been reported to be severe. ${ }^{1-3,19,20}$ However, only a limited number of studies evaluated disease outcomes, CPO patients from Korea showed relatively favorable post-operative outcomes. ${ }^{13,15}$ The TZ, a colonic segment connecting proximally dilated and distally non-dilated segments has been described in Korean CPO patients. ${ }^{9,10,13-15,21}$
Consistent observations of the $\mathrm{TZ}$ in previous studies evaluating Korean CPO patients implied that the distinct clinical characteristics of these patients may be associated with the presence of TZ. ${ }^{9,10,13-15,21}$ Through detailed pathological analysis of the resected specimens, we found that the ganglion cell density, was significantly decreased in $\mathrm{TZ}$ compared to proximal dilated and distal non-dilated segments $(P<0.001)$. Interestingly, the ganglion cell density in the dilated colon located proximal to the $\mathrm{TZ}$ was not decreased as in the non-dilated distal colon. These results are consistent with our previous study, which suggested the $\mathrm{TZ}$ was the principal site of functional obstruction. ${ }^{10}$ We found that the circular muscle from the $\mathrm{TZ}$ was less responsive to contractile stimuli and nNOS-positive cells were depleted in the $\mathrm{TZ} .^{10}$

Previously, a group of pediatric patients, mainly from Japan, similar to Korean CPO patients with TZ has been described. ${ }^{11,22-24}$ These patients were classified as having "allied disease of Hirschsprung's disease" ${ }^{\text {23 }}$ or more commonly as having "acquired isolated hypoganglionosis (AIHG)."22 Although given a different label and patients had a different age range, similar clinical and pathological characteristics as Korean CPO patients with TZ were observed in pediatric AIHG patient group. Above all, a focal intestinal segment with a reduction in the number of ganglion cells was found. ${ }^{11,22,23,25,26}$ Second, the involved segment was mainly the colon, ${ }^{11,25,26}$ and the clinical course of this group of patients was relatively favorable. ${ }^{23}$ We think Korean CPO patients with TZ may be a late-onset form of pediatric AIHG. Taken together Korean CPO with TZ and pediatric AIHG may be a subtype of CPO with favorable outcome, which is more prevalent in Asian countries.

In some cases of pediatric AIHG, eosinophilic infiltration and ischemic changes in addition to segmental hypoganglionosis have been observed. ${ }^{22,25}$ We found specific pathologic features including, eosinophilic ganglionitis, CMV infection, ischemic changes, heterotopic myenteric plexus in addition to TZ-associated hypoganglionosis in $16.2 \%$ of the TZ $(+)$ group. Pediatric AIHG can be ascribed to ischemia and viral infection, ${ }^{22}$ which may also contribute to ganglion cell degeneration and loss in our CPO patients. An autoimmune mechanism triggered by viral infections, such as herpes simplex virus (HSV) or CMV, may indeed result in loss of ganglion cells as also occurs in some peculiar neuropathies, such as achalasia. ${ }^{27}$ To confirm this hypothesis, we performed HSV immunostaining in selected cases. However, no HSV positive cells were identified. Further studies with larger sample sizes will be needed to evaluate the etiology and pathogenesis of $\mathrm{CPO}$ with TZ.

Herein, a quantitative decrease in ICC along with hypoganglionosis was identified in a subset of cases. However, the ICC 
decrease was much milder than that of the ganglion cell density and was neither directly proportional to the decrease of ganglion cells nor associated with post-operative outcome. Contrary to our results, there have been conflicting results about the relationship between neuropathy and ICC. ${ }^{11,28}$ Thus, the clinical impact of ICC depletion in the context of hypoganglionosis should be further evaluated.

Our study has some limitations that should be addressed. First, because we only included patients who were refractory to medical treatment and ultimately underwent surgery, the impact of $\mathrm{TZ}$ on the response to medical treatment in Korean CIPO patients was not evaluated. Second, only 2 patients belonged to the TZ (-) group and only one patient with visceral myopathy. This might be due to the lower prevalence of visceral myopathy in the Korean population than in Western countries ( $5 \%$ vs $20 \%$ ). ${ }^{6,13,15,29}$ Third, we used $\mathrm{H} \& \mathrm{E}$ staining to detect ganglion cells and did not perform immunostaining using anti-Hu C/D antibody, which is a more precise method. However, the differences in ganglion cell density between hypoganglionic and non-hypoganglionic segments were significant; thus, the inferior precision of $\mathrm{H} \& \mathrm{E}$ staining may be tolerated and would not affect the analysis result as a whole.

In summary, our study determined that Korean $\mathrm{CPO}$ patients present distinct characteristics from Western CIPO patients, namely: (1) mainly colon involvement in Korean patients vs small bowel involvement in Western patients; (2) TZ with hypoganglionosis, commonly observed in Korean patients, but rare in Western patients; and (3) relatively good prognosis after removal of the TZ in Korean patients. Considering the decreased ganglion cell density observed in the TZ of most Korean CPO patients, the TZ could be the main site of obstructive symptoms. Mechanisms including ischemia, inflammatory (eosinophilic ganglionitis), and neurotropic virus (CMV) infection can lead to hypoganglionosis. This subset of patients was associated with poor post-operative outcomes. Further studies involving genetic evaluation are required to better elucidate the pathophysiology and specific characteristics of $\mathrm{CPO}$ with $\mathrm{TZ}$, which manifests as a typical Eastern phenotype of severe dysmotility.

\section{Supplementary Materials}

Note: To access the supplementary tables and figures mentioned in this article, visit the online version of Journal of Neurogastroenterology and Motility at http://www.jnmjournal.org/, and at https://doi.org/10.5056/jnm18121.
Acknowledgment: The authors thank Roberto De Giorgio, professor at the Department of Medical Sciences, University of Ferrara, Italy, who contributed to the manuscript preparation.

Financial support: This study was supported by a grant from the Korea Health Technology R\&D Project through the Korea Health Industry Development Institute (KHIDI), funded by the Ministry of Health \& Welfare, Republic of Korea (No. $\mathrm{HI} 15 \mathrm{C} 3078$ ) and by the fund from the Ministry of Trade, Industry \& Energy (MOTIE, Korea) under Industrial Technology Innovation Program (No. 10063408).

\section{Conflicts of interest: None.}

Author contributions: Planning and conducting the study: Eun Mi Song, Jong Wook Kim, and Seung-Jae Myung; collecting data: Eun Mi Song, Jong Wook Kim, Sun-Ho Lee, Kiju Chang, Sung Wook Hwang, Sang Hyoung Park, Dong-Hoon Yang, Kee Wook Jung, Byong Duk Ye, Jeong-Sik Byeon, Suk-Kyun Yang, Hyo Jeong Lee, Chang Sik Yu, Chan Wook Kim, and Seung-Jae Myung; interpreting data: Eun Mi Song, Seong Ho Park, and Jihun Kim; drafting the manuscript: Eun Mi Song, Jihun Kim, and Seung-Jae Myung; critical revision of the manuscript for important intellectual content: Kee Wook Jung, Byong Duk Ye, Jeong-Sik Byeon, Suk-Kyun Yang, and Hyo Jeong Lee; and guarantor of the article: Jihun Kim and Seung-Jae Myung.

\section{References}

1. Stanghellini V, Cogliandro RF, De Giorgio R, et al. Natural history of chronic idiopathic intestinal pseudo-obstruction in adults: a single center study. Clin Gastroenterol Hepatol 2005;3:449-458.

2. Lindberg G, Iwarzon M, Tornblom H. Clinical features and long-term survival in chronic intestinal pseudo-obstruction and enteric dysmotility. Scand J Gastroenterol 2009;44:692-699.

3. Amiot A, Joly F, Alves A, Panis Y, Bouhnik Y, Messing B. Long-term outcome of chronic intestinal pseudo-obstruction adult patients requiring home parenteral nutrition. Am J Gastroenterol 2009;104:1262-1270.

4. Rosa-E-Silva L, Gerson L, Davila M, Triadafilopoulos G. Clinical, radiologic, and manometric characteristics of chronic intestinal dysmotility: the Stanford experience. Clin Gastroenterol Hepatol 2006;4:866-873.

5. Stanghellini V, Cogliandro RF, de Giorgio R, Barbara G, Salvioli B, Corinaldesi R. Chronic intestinal pseudo-obstruction: manifestations, natural history and management. Neurogastroenterol Motil 2007;19:440-452.

6. Lindberg G, Tornblom H, Iwarzon M, Nyberg B, Martin JE, Veress B. Full-thickness biopsy findings in chronic intestinal pseudo-obstruction and enteric dysmotility. Gut 2009;58:1084-1090.

7. De Giorgio R, Sarnelli G, Corinaldesi R, Stanghellini V. Advances in our understanding of the pathology of chronic intestinal pseudo-obstruction. 
Gut 2004:53:1549-1552.

8. Ohkubo H, Iida H, Takahashi H, et al. An epidemiologic survey of chronic intestinal pseudo-obstruction and evaluation of the newly proposed diagnostic criteria. Digestion 2012;86:12-19.

9. Do MY, Myung SJ, Park HJ, et al. Novel classification and pathogenetic analysis of hypoganglionosis and adult-onset hirschsprung's disease. Dig Dis Sci 2011;56:1818-1827.

10. Do YS, Myung SJ, Kwak SY, et al. Molecular and cellular characteristics of the colonic pseudo-obstruction in patients with intractable constipation. J Neurogastroenterol Motil 2015;21:560-570.

11. Ohkubo H, Masaki T, Matsuhashi N, et al. Histopathologic findings in patients with idiopathic megacolon: a comparison between dilated and non-dilated loops. Neurogastroenterol Motil 2014;26:571-580.

12. Matsui T, Iwashita A, Iida M, Kume K, Fujishima M. Acquired pseudoobstruction of the colon due to segmental hypoganglionosis. Gastrointest Radiol 1987;12:262-264.

13. Choe EK, Park SH, Park KJ. Colonic pseudo-obstruction with distinct transitional zone in adult constipation patients: pathological analysis and results of surgical treatment. Am Surg 2011;77:736-742.

14. Lee KJ, Jung KW, Myung SJ, et al. The clinical characteristics of colonic pseudo-obstruction and the factors associated with medical treatment response: a study based on a multicenter database in Korea. J Korean Med Sci 2014;29:699-703.

15. Han EC, Oh HK, Ha HK, et al. Favorable surgical treatment outcomes for chronic constipation with features of colonic pseudo-obstruction. World J Gastroenterol 2012;18:4441-4446.

16. Iwase H, Sadahiro S, Mukoyama S, Makuuchi H, Yasuda M. Morphology of myenteric plexuses in the human large intestine: comparison between large intestines with and without colonic diverticula. J Clin Gastroenterol 2005;39:674-678.

17. Ooms AH, Verheij J, Hulst JM, et al. Eosinophilic myenteric ganglionitis as a cause of chronic intestinal pseudo-obstruction. Virchows Arch 2012;460:123-127.

18. Lee H, Kang D, Kim H, Cho B, Jang J. Unusual histology of eosinophilic myenteric ganglionitis: a case report. J Pathol Transl Med
2017;51:320-324.

19. Mann SD, Debinski HS, Kamm MA. Clinical characteristics of chronic idiopathic intestinal pseudo-obstruction in adults. Gut 1997;41:675-681.

20. Di Nardo G, Di Lorenzo C, Lauro A, et al. Chronic intestinal pseudoobstruction in children and adults: diagnosis and therapeutic options. Neurogastroenterol Motil Published Online First:29 Jan 2017.doi: 10.111/nmo12945.

21. Kim HJ, Kim AY, Lee CW, et al. Hirschsprung disease and hypoganglionosis in adults: radiologic findings and differentiation. Radiology 2008;247:428-434.

22. Taguchi T, Masumoto K, Ieiri S, Nakatsuji T, Akiyoshi J. New classification of hypoganglionosis: congenital and acquired hypoganglionosis. J Pediatr Surg 2006;41:2046-2051.

23. Taguchi T, Ieiri S, Miyoshi K, et al. The incidence and outcome of allied disorders of hirschsprung's disease in Japan: results from a nationwide survey. Asian J Surg 2017;40:29-34.

24. Meier-Ruge W, Bruder E. Histopathological diagnosis and differential diagnosis of Hirschsprung's disease. In: Holschneider AM, Puri P, eds. Hirschsprung's Disease and Allied Disorders. 3rd ed. New York: Springer, 2008:185-197.

25. Yoshimaru K, Taguchi T, Obata S, et al. Immunostaining for $\mathrm{Hu} \mathrm{C} / \mathrm{D}$ and CD56 is useful for a definitive histopathological diagnosis of congenital and acquired isolated hypoganglionosis. Virchows Arch 2017;470:679685.

26. Dingemann J, Puri P. Isolated hypoganglionosis: systematic review of a rare intestinal innervation defect. Pediatr Surg Int 2010;26:1111-1115.

27. Pandolfino JE, Gawron AJ. Achalasia: a systematic review. JAMA 2015;313:1841-1852.

28. Wedel T, Spiegler J, Soellner S, et al. Enteric nerves and interstitial cells of Cajal are altered in patients with slow-transit constipation and megacolon. Gastroenterology 2002;123:1459-1467.

29. Knowles CH, Silk DB, Darzi A, et al. Deranged smooth muscle alphaactin as a biomarker of intestinal pseudo-obstruction: a controlled multinational case series. Gut 2004;53:1583-1589. 